\title{
Metropolitan Mothers: Mothers, mothering and paid work
}

\author{
Carol Vincent, Stephen J. Ball \& Soile Pietikainen
}

Dr Carol Vincent

School of Educational Foundations and Policy Studies

Institute of Education

59 Gordon Square

LONDON

WC1H ONT

Tel: $\quad 02076126915$

Fax: 02076126366

Email: c.vincent@ioe.ac.uk

To be published in Women's Studies International Forum, vol.27, nos.5/6, 2004 


\section{Biographical statements}

Carol Vincent is currently directing this research project on parents' choice of childcare. Other research interests include parents' relationships with the education system and she has published widely in this area. Her most recent book is an edited collection, entitled Social Justice, Education and Identity (RoutledgeFalmer, 2003). She has two children.

Stephen J. Ball has written and researched extensively, particularly in the area of social class and education policy. His new book, Class Strategies and the Education Market: the Middle Class and Social Advantage (2003) is published by RoutledgeFalmer. He lacks the 'pleasures' of fatherhood.

Soile Pietikainen is the Research Officer on the choice of childcare project. Her previous work has included a study of the experiences of au pairs in the UK. She has two children. 


\title{
Metropolitan Mothers: Mothers, mothering and paid work
}

\begin{abstract}
This paper reports on the interim findings from a two year ESRC (Economic and Social Research Council) -funded project exploring parental choice of child care for pre school children. The fieldwork is based in two predominantly middle class areas in London. The vast majority of the respondents to date are women, many of whom are in paid employment. This paper draws on the literature about mothering, motherhood and identity to explore how these professional middle class women experience shifts in their self-identity. It considers how the women respond to the emotional and physical labour required of them by their roles as both worker and mothers, how they negotiate the tensions between the two, and how couples adapt to managing employment, childcare and a household. It also briefly considers the childcare roles and practices of the fathers. It concludes that despite the social and economic advantages of these middle class families, the adults are not presenting a serious challenge to a traditional understanding of family relationships.
\end{abstract}




\section{Metropolitan Mothers: Mothers, mothering and paid work}

\section{Introduction}

Anyone who talks about the family must also discuss work and money (Beck 1992, p.103)

We are writing in a context where to be a mother and not to work is becoming increasingly unusual. In recent years the UK has seen an enormous rise in the numbers of women with young children returning to work. Between 1984 and 2000 the employment rate for women with children under five rose from $27 \%$ to $54 \%$ with full time employment accounting for nearly half of this increase (Mooney 2003, p.131). The Daycare Trust (a pressure group campaigning for improved child care) reported that in 2001 almost 58\% of mothers with a child under five were in work, (Daycare Trust 2001a).

Despite this influx of mothers into the workforce, a recent study 'Winners and Losers in Labour Markets: Young Adults Employment Trajectories' by Bradley, Fenton \& West found that traditional attitudes regarding paid work and childcare in the UK remain robust (final report for ESRC award R000238215 posted at www.regard.ac.uk ). A quarter of the young women interviewed in Bristol said their ideal was 'father working, mother not' whilst a further $38 \%$ said it was 'father working [full time], mother part time'. In this paper we consider whether the respondents in our research (also funded by the Economic and Social Research Council, the ESRC), a highly educated group of middle class women in their 30s and 40s, share the views expressed by these younger women (from a range of social class backgrounds) in Bradley et al's broader study. Clearly the increase in the number of mothers in paid work constitutes considerable social change. We ask how these professional middle class mothers respond to the emotional and physical labour required of them by their roles as both worker and mothers, how they negotiate the tensions between the two, and how couples adapt to 
managing employment, childcare and a household. Arguably, it is this social group of women who, by virtue of their relative affluence, are in a position to create new forms of and approaches to combining paid work and motherhood. However, we suggest that 'traditional' responses, whereby the mother slows down or gives up her career and takes on the prime responsibility for caring for children and organising the care of others, are predominant within our respondent group, and we then turn our attention to the longevity and robustness of such traditional arrangements.

\section{The study}

This paper is part of a series analysing data collected for a project (ESRC award no. R000239232) investigating choice and provision of pre-school child care. We are interested in the developing and dynamic pre school education and care market, and the interactions of parents with that market. We are focusing on professional middle class users, sometimes referred to as members of the 'service class', a sizeable group of users in the formal market place where the costs involved in accessing care are high, especially in London, the setting for our research (costs of $£ 9,000$ per annum have recently been cited for a nursery place for a two year old in London, Hall 2004 ${ }^{\mathrm{ii}}$ ). The research as a whole involves a respondent group of 57 mothers (20 of whom were re-interviewed to track changes in their care arrangements) and 14 fathers, (interviewed only once). However this interim paper focuses on an initial group of first round interviews with 50 mothers. Towards the end of the paper we also refer to two interviews, additional to the main 50. These are with two fathers who were recruited as part of our last group of respondents. We located the research within two inner London areas, one, Stoke Newington in North London and the second, Battersea, in South London (the rationale behind this is further explained in Vincent et al 2004). The respondents were recruited in a number of ways: we placed adverts in child friendly shops and cafes in the areas and in local area parenting newsletters and those of the National Childbirth Trust. We also 'snowballed' from our original respondents to others. Our original contact was in all cases, but one, with the mother, but in the later stages of the project we sought to include men's views, by interviewing them alone or as part of the re-interview with their partners (as they chose). 
Our research cohort is a very particular one, with this paper, as we noted above, referring to a group of 50 women. They all have degrees, and ten have PhDs. These are women who have or had and had been educated to have, careers, rather than jobs, careers for which they had trained and studied and which they enjoyed for their own sake. Catherine Hakim in her study of mothers' attitudes towards paid work, argues that 'graduate women .... do not automatically prefer a career over family life' (2000, p.94), but that higher education does give women access to and the expectations of a 'reasonably interesting and well-paid job' if they are in employment (2000, p.96), an apt description of our respondents. Like the middle class respondents in McMahon's (1995) study of North American working mothers, they made the choice of 'adding children to their lives: work was taken for granted... [they made] personal and financial investments in work and career that they found rewarding' (1995 p.227). When they have children our respondents, like McMahon's have to work to reconcile a newly-acquired identity as 'mother' with other existing identities as 'worker' (which are well established), because of the different demands of the roles. One of the respondents in our research, Felicity, explains her attitude to paid work in the following terms

I loved going to work and I've always been a huge feminist. I went to one of those kind of girls' grammar schools that was incredibly correct in terms of getting people out doing maths and sciences..I just picked up this whole culture about women being able to do anything..... like the fact that I earn more money than my husband does..I found it very good to be able to go back to work [after having a child]. I'd find it incredibly economically marginal. I found I hated being marginalized, just being seen as a mother.... So it was nice to get back to work but I kind of wanted the balance, I wanted to be able to have my cake and eat it, as in spend some time with him and some time working...I wasn't ever going to be a very good full-time mother and I think I would have got quite unhappy if I had been (Felicity, Battersea, (B) self employed writer of business texts and lecturer, works part time) 
Felicity would seem to present a stereotype of the successful middle class, professional woman. She and her husband between them earn enough to cover $£ 35-40,000 \mathrm{pa}^{\mathrm{iii}}$ in childcare costs (they have a nanny and her son also attends some sessions at a private nursery). She travels abroad, she works from home free from institutional constraints, she does not feel guilty about not caring full time for her son, she wants in that infamous phrase 'to have it all'. Indeed she generally manages the balancing act that requires, but running alongside her acknowledgement of privilege is another narrative revealing of both stress and distress.

If you had spoken to me last December I'd be completely, 'this is awful, this is terrible, working with children and childcare and it's really dreadful'. Well it is really hard work and it is really dreadful anyway, but I'm just more positive about recent experience. Last December I was completely in despair about the whole thing....How on earth do you keep all those things going? How do you juggle it all? .....There was one occasion with our old nanny where I had to go to a big meeting and I couldn't go and literally people turned up at Kings Cross expecting me to be on the train and I wasn't there which was one of the most dreadful experiences of my life and they never paid their bill...even though they were paying for other things too. I let them down on a really big occasion...I was in floods of tears. I just sat on the floor and howled because there wasn't much else to do really (Felicity, B)

If anyone could be expected to manage childcare and work, then one would expect it to be Felicity with all her advantages and, not least, her certainties. Yet when things go wrong it is still she who is left to pick up the pieces. This is not a paper about how even affluent middle class mothers cannot 'have it all'; the tabloid press often appear to rejoice in tales of 'career women' who have given up their lucrative and high status positions and returned home to look after their children (Benn 1998), and this reassertion of traditional role models is, needless to say, not a stance we share. It is rather an attempt to understand and document two inter-related features of the relationship between motherhood and paid work. The first and easiest of these tasks is to identify the various practical and tangible 
settlements which mothers have made between employment and mothering, and to describe the constraints under which they operate. The second task is to reveal more nebulous settlements, how these highly educated women resolve the tensions between two competing discourses, one which values paid employment, especially in high status professional and managerial posts, and another set of disparate discourses around contemporary mothering which both value and devalue the work of caring for young children. We suggest this discursive tension is indicative of a fundamental confusion in society about the status of caring for young children, and the role of mothers, fathers and others in that task. As Grace (1998) argues,

On the one hand, mothers are ascribed an almost holy status, providing some recognition of their contribution, but locking them into expectations of extreme self sacrifice. On the other hand their work is considered non-work, is not economically rewarded and is not generally respected, (p.401) (also Hondagneu-Sotelo 2003)

\section{The respondents}

To recapitulate: the women who participated in our research project lived in two areas of inner London, Battersea and Stoke Newington, both of which have significant, but somewhat different, middle class populations (see Vincent et al 2004, Ball et al 2005) They are mostly white (except one, although a further two were in mixed race relationships), mostly heterosexual (except one), and mostly in partnerships (except $\left.o^{\mathrm{i}}{ }^{\mathrm{i}}\right)$. They were as we noted above, highly educated. It is not the norm for this group of women to stay at home and not to go out to work. For this reason caring work is not necessarily central to their self image in the way that it is for the group of working class women assembled by Bev Skeggs (1997). Her respondents, students on Further Education 'caring' courses, frequently set their practical experience of caring (for children or elderly) over the academic component of the course, and saw their practical abilities as innate: they were 'naturals'. 
The women in our study who work do not hesitate to pay for care. Their attitude contrasts with those expressed by women in Jordan et al's (1992) study of the inhabitants of a working class council estate in Exeter. Bill Jordan and his colleagues comment that interviews with the mothers revealed that 'the obligation to put the children's needs first is binding' (p.135) often over and above the needs of paid work and almost always above the needs of the mothers themselves. Nonetheless, together with Hays (1996), we suggest, that the need to construct a morally adequate account of oneself as mother requires women of all classes to present their prioritisation of their children's needs, as becomes apparent below. The class specific differences between the working class mothers in the Exeter study and also those in a study by Edwards and Duncan (1996), and the middle class women in our study are revealed in the different practical and discursive ways in which these moral accounts are produced, that is within different 'local moral geographies of mothering' (Holloway 1998. A closer application of this concept to our project is part of our current work-in-progress). For these working class respondents paid care is seen as inappropriate and unaffordable, and care by family members and close friends is almost always preferable. By contrast our middle class respondents engage largely with the formal market in childcare (qualified nannies, registered childminders, private day nurseries), but also, in a few cases, with the informal market (unqualified carers, often recent immigrants) out of which are made complex patchworks of care, which include the mothers themselves.

These patchworks differ from one another. It is possible to identify a variety of responses amongst our respondents as they sought to resolve what Hays (1996) calls the 'cultural contradictions of motherhood' arising from two opposing logics, that of the private family sphere and that of the public marketplace. Some of the women had chosen to give up paid work, others shortened their hours and slowed the pace of their careers. The vast majority had adapted their careers in some way. Out of 50 respondents 25 worked part time, 18 were at home full time, 7 worked full time at the time of the interview or were on maternity leave and planning to return full time. However, the numbers do not convey the range of different resolutions, the variations in attitudes and circumstances. Working part time for instance varies between 4 days a week and 10 days a month. Some 
gave up work when their first child was born and have no plans to return, others gave up more reluctantly as working and mothering became too stressful, or childcare too expensive. Others have moved between full time, part time, and no paid work as circumstances have changed (usually the arrival of a new baby). Hays (1996) talks of the 'mommy wars' between two stereotypes, a stay-at-home baker of cookies and a superwoman effortlessly juggling home and career. For many of our London respondents the reality is more fluid as their work and care scenarios change as the children grow and circumstances alter. The difficulties of finding a balance between paid work and caring for children is apparent in the high number of women who now work part time. They "'live a contradiction" by juggling options, possibilities and disappointments' in a context in which a 'socially organised' system for women to combine satisfactory 'work and family' does not exist (Padfield \& Proctor 1998 p.249, cited in McKie et al 2001 p.244, also Grace 1998, p.407). Hakim (2000) understands this diversity as evidence of women making different kinds of positive choices, and with regard only to our relatively privileged sample we mostly agree (our respondents often noted their 'luck' in being in/not being in paid employment as they chose). However, Hakim continues by saying that 'preference theory suggests that a change of emphasis is need in sociological research, away from structural factors...towards the values and preferences that will shape behaviour in the twenty first century' (2000, p.278). This stance, and Hakim's emphasis on 'individualised preference' (Duncan et al 2003, p.325) concerns us because we are acutely aware that many of our respondent group are privileged in having employment which allows them a high degree of autonomy, flexibility and control, which is not available to many other working women (see Reynolds et al, 2003, on the importance of this for mothers' perceptions of paid work). Furthermore, as Hakim acknowledges, our study and those of many others (eg Hochschild 1989, Hays 1996, McMahon 1995) illustrates how deeply embedded women remain within gendered divisions of labour which pre-empt the possibilities of choice.

The rationale for the decisions mothers took vary considerably (see also Hakim 2000). We can place the respondents on what we have called an investment continuum ranging from investment in full time mothering to investment in full time paid work. Some gave 
up because they found it impossible to continue to do their paid work, because of the demands of long hours, or the difficulty in finding childcare with which they were happy. A few had no clear career plan. Others had no desire to continue in paid work once they had children. Some are in part time work because they made a clear choice to do so, wanting a balance between work and being with their children, others because they found full time work too difficult to manage, as they struggled to meet the demands of inflexible jobs and employers. A consideration of different women at different points in the continuum illustrates individual settlements, often temporary or fragile, between the demands of motherhood and paid work, settlements made at both practical and ideological levels. Let us look at some of these.

\section{Working women}

\section{Staying at home}

Generally the justifications given by mothers for staying at home, especially those who said they had made a clear choice to do so were less detailed than justifications which women put forward to explain their paid work. In this sense, being a full time carer of one's own children is understood as 'natural', 'normal' and needing little explanation, still less justification. Mothers spoke of their emotional commitment to being at home with children ('I was completely changed by having a baby...it just occurred to me 'I didn't have to go back it was like a revelation' Jackie, Stoke Newington, SN), and their

desire to care for their children themselves. However, in making the decision to stop paid work, the women exchange their high status careers for a caring role, doing so in a society which devalues caring jobs (taken in the most part by poorly paid, working class young women). Certainly some of our providers spoke about the way in which caring for children is not perceived as skilled work, but rather as something 'any old person from the street' can do (Nursery manager, SN). One childminder commented similarly,

I think [people] think childminders are quite thick and quite stupid, and you're only doing this [job] because you couldn't do anything else. And it's like when 
[parents] find out that I've got a degree and stuff, they're kind of 'why are you doing this if you've got a degree? You could work' (childminder, SN)

In this climate, where caring is casually disconnected from 'proper' work, mothers have re-make those connections for themselves and others, emphasising that mothering is an important and valuable job, or even a 'vocation' as one refers to it. It is a maternal responsibility, almost a moral obligation to care for your own children. 'Own' is the keyword here; it serves to differentiate these mothers from low paid, low status carers. We are interested in whether these middle class mothers do still perceive a drop in status , from professional worker to mother. This is a question we are exploring in repeat interviews which are currently on-going.

Whilst I palm him off on someone else [a nursery ] for two days a week I didn't actually have him for someone else to bring him up....Some people think should I give up work or shouldn't I? I didn't have that dilemma, I knew what I wanted to do (Sandra, Battersea, used to be in PR)

When I put her in [one nursery] I cried every time I left her. She cried too... it was awful...And I did have slight feelings of guilt obviously because I wasn't working and it was my job to look after [her]. [Now] she doesn't want to hang around with me all day.. so I don't have any guilt any more about dropping her off. But I do still want to be there, you know, even when she's at school. I don't want her to be a latchkey kid (Sally, Battersea, used to be in PR)

I didn't really [ever consider getting help]...15 months apart is quite close together, [but] I thought they'll just have to learn...there were days when it was absolutely awful and I really could have used some help, but I think it's a learning process...that's all part of being in a family...I've got a lady who comes and helps clean but the childcare I think, I wanted to do... I value what I do...I think that it is a worthwhile thing.....he's [husband] really lovely and he often tells me he couldn't do it and that I'm doing a good job and that I've got 
patience and all that sort of stuff that he doesn't have, which is nice.... When it's really horrible there's not a lot you can [do]. You know some days aren't good, like any other job. (Suzannah, SN, used to be recruitment consultant).

In the back of mind I knew I wanted to slip out of the working world for a while..... I felt my role as a mother is to bring up my children myself, and that's, you know, my vocation, I've chosen to do it and I should jolly well get on and do it, er, but as we're expecting a third and I was shouting at my children more and more, they were 2 boisterous little boys and I just thought I'm not, why am I fighting it, do you know what I mean? It's just things like [the proposed au pair] can help me just be nicer to my children because I've got to try, I found I was always ignoring them because you're trying to get on with tasks, the house tasks and the phoning and the, or you're sticking them in front of the video for hours because you're trying to organise something, or cook, or whatever.... I just felt I wanted to enjoy my children, I felt suddenly look at [oldest son], and although he's 3, he seems so grown up, and I thought 'well where has it gone?" It's gone in me trying to stuff the washing machine and shouting at him because he's ripping something off the wall, and I thought I really want to enjoy this third one, I don't want to miss it, (Eleanor, B, used to be in PR)

There is a clear distinction in the women's words (if not perhaps in their practice) between staying at home to be with the children and staying at home to be a housewife. Eleanor's transcript is unusual for the extent to which domestic chores appear. Walkerdine \& Lucy (1989) argue that housework for middle class mothers goes underground, transformed from dullness into a site of pedagogy for their children. This is quite a difficult task for mothers to achieve particularly if their children do not want to co-operate. In any case as Eleanor and Suzannah realise, au pairs and cleaners make the demands of domestic labour less pressing. The working class mothers in Walkerdine \& Lucey's study are clear that housework is their job, and must often be prioritised over playing with their children. For the mothers in our sample, housework is a job from 
which they can extract themselves by buying in others. Housework interferes with the primary focus on the child. Childcare and the mother-child relationship is special in all this - special for the mother as well as the child, an opportunity to be enjoyed. However, such enjoyment requires particular conditions of care.

There are also risks attached to staying at home: a risk of loss of self and identity, well expressed by Jackie,

I'm not always entirely happy with the situation [not working] I can't quite relax about it. I'm a bit nervous about letting go completely of work and losing my confidence, and I also have days of complete frustration with [the children], so I feel I ought to do something probably...basically in the next year I want to make some kind of decision about what I want to do, I can't just leave it (Jackie, SN, was in publishing/translation)

There is the perception that society pays only lip service to value of mothering, whereas in the world of work, by contrast you 'are valued for what you can contribute' (Margaret). As Felicity points out above to be a mother is to be marginalized in many situations. Similarly Eleanor talks of 'slipping out of the working world'. To be a mother is to be outside of 'society' and wholly inside 'family'. And being inside family is a risky place to be. Mothering is hard work. Whilst Beck and Beck-Gernsheim (1995) argue that motherhood can be a refuge from the soberly, impersonal working world, where emotion is largely frowned upon, seen as a distraction, the emotion derived from a home with small children can be raw. One mother talks of 'being consumed' by her children (Tina); another of the 'emotional rollercoaster' of having a baby (Anjali), and another about the utmost importance of having other mothers as support (Sandra). There is guilt about buying in care to give time for themselves, rather than 'having' to buy care because of work, guilt about wanting to be away from your children; and fear (see Jackie above) of losing one's ability to engage with the 'outside' world (also Vincent 2000). The risks of staying at home are starkly summarised by Hays: 'In short, the world presents, and 
mothers experience, the image of the lazy, mindless, dull housewife - and no mother wants to be included in that image' (1996 p.138)

\section{In the labour market}

Those of our respondents who remained involved in the labour market spoke of the liberation of working. This was meant both in the financial sense and also in terms of maintaining a particular and socially valued sense of self and a series of relationships separate and distanced from their children.

With [oldest child] someone had said to me 'oh you're gonna find the first day you give over your child really difficult, it's really tough'. And I was in the car singing along to the radio, my own music rather than bloody Wheels on the Bus, just thinking this is absolutely fantastic (Kathryn, B, part time speech therapist)

McMahon points here to the influence of 'cultural rhetorics of individualism' (1995, p.2), For the middle classes in particular, she argues, a good mother demonstrates 'commitment without engulfment', and employs 'strategies of separation' (ibid p.153/6). For middle class women 'employment is constructed as an opportunity for the expression of self' (ibid p.157). Concomitantly, Jordan et al (1994) point to the moral imperative operating amongst the middle classes to 'make something of yourself'. In these circumstances, pregnancy and having children constitute a challenge to working identity (Bailey 1999 p.341). Returning to work, particularly to part time work, can lead to a new resolution, a new alignment between different facets of identity. As Linda and Debra say,

I positively want to work and I know I'm a better person for working, a happier person for working (Linda, B, charity consultant).

It was quite straightforward [returning to work] because I work for a big organisation which has...flexible working plans I think they're called. What I 
did was I met my immediate boss about a month before [I was due to return] just in a coffee bar, just you know 'let's meet up with the baby' and she said 'what would you like to do?' and I said 'I'd like to work three days' and that was it...I actually like going to work, [working part time] I think has really improved the quality of my life, not being in the office all week (Debra, BBC producer).

Debra refers here to the way in which motherhood can also be a positive interruption of the damaging effects of 'engulfment' by one's employment.

A few respondents also spoke about performing socially useful work. Bailey notes that some types of work and mothering have important discursive similarities - redolent of responsibility, service, stability, interest and value (rather than status or money). Some jobs have a moral worth in the same way mothering does, but on a larger and more public stage (Bailey 1999 p.342). Even so, within families there is always the possibility that the worth of work and the worth of the worker are reduced to a financial calculation.

He and I have very different perceptions as to why one works. His is very definitely you work to bring money in to support the family. And the more money you get, the better you are at fulfilling that role, and therefore the more valuable your job is. My view is ....what do I want to do that's interesting and useful? And so he cannot understand why I should want to go to work when I'm paid so crap and it sort of takes over...he can't see why when I've got the option of staying at home and looking after the children, and meeting friends for lunch and playing tennis why I don't do that. Because it doesn't bring any money in so why do I choose to put myself under pressures that I put myself under by going to work.....I'm writing up a $\mathrm{PhD}, \ldots$...so I have to work, I work most evenings and I'm getting up sometimes in the morning as well before the children wake up so that I can do a couple of hours before they get up......He will tolerate the intrusion of it as long as it doesn't intrude in any way......But to me working is fundamental to how you see yourself and how you see your role 
in society and your role with other people. (Kathryn, B, she is a part time speech therapist, he is a lawyer)

Work here is central to identity and develops a sense of self esteem, that one can contribute to society, not indirectly through the private sphere of family, but directly working in the public arena. We also glimpse here another aspect of the calculus of balance for these women - the absence of fathers in the discourse of care, but the need nonetheless to take partners into account in arriving at some kind of balance or resolution of identity and responsibility.

Furthermore, several women appeared to offer justifications for continuing to work, by asserting that they were not 'natural' mothers and contrasting themselves with an ideal 'natural' mother who consistently enjoyed being with her children, was skilled at stimulating them, was never in a bad mood, and was fulfilled by her role. Therefore, as they saw it, their working was to their children's advantage. Others, trained and professional, could do a better job.

By the time I'd started to work full time again I was desperate not to be, I'm not a natural stay at home, raising kids and not doing anything else, I was climbing the walls (Mia, SN, works now for NGO. Used to work as arts administrator)

I do not believe my children would be better off if I was staying at home looking after them...I think they'd have all the vagaries of me as an individual...if I'm in a ratty mood for whatever reasons, that's going to be difficult. And I don't think I've got the skills to...I can spot some of the stuff eventually, but I think I'm probably less ambitious for them, perhaps then the nursery is. So I tend to see them playing with something at the nursery and then think 'oh that would be a good idea to get at home'... or I can be surprised by what they're doing. And I don't think I have a natural, a sort of, that doesn't that doesn't all come naturally to me. (Monica, B, public sector accountant) ${ }^{\mathrm{v}}$ 
Work/childcare tensions: 'the politics of time' (Benn 1998)

Stephens' (1999) study of female hospital doctors who work part time and have children is an example of the workings of the 'politics of time'. For the women, time is 'earned' (she gives examples of women attempting to plan the conception of their children to allow them to start work part time and still progress with their careers), or 'bought' (by paying for childcare or domestic help). Time for themselves has to be 'stolen' and their own leisure time was often subsumed by the supervision of their children's activities.

Stephens' general point about the gendered nature of time, applies to all our respondents given that in all cases to date, it is women who take responsibility for finding and managing childcare. The specific focus of her study - hospital doctors - points to the variations between occupations in terms of the flexibility which they offer. This argument - the importance of the organisational ethos and culture for how mothers experience paid work - is also made by Crompton (2001) in her study of GPs and bankers, and Reynolds et al (2003), in their study of mothers who work for two contrasting employers, a public sector hospital and a private accountancy firm. Sometimes, as with Margot (from our study and quoted below), a particular individual in an organisation can make a difference. Some jobs combine well with childcare, better than others, allowing mothers (it usually is mothers) to work part time (see Debra above. Also Monica who works in the public sector for a 'paternalistic employer' and is in a senior position which allows her to introduce some flexibility into her hours and work at home one day a week.). Other careers particularly for those who work in the private sector, often in the financial sector of the City of London, emphasise presentee-ism and long hours, where the ethos demands that one submits to the "male model of work often at considerable personal cost' (Phoenix 1991 p.203; see also Pearson's 2002 fictional account of a middle class City mother). Here the ideal employee is what is termed in the USA a 'zero-load' worker (the term deriving from Silicon Valley), one who has no domestic commitments, can be flexible and mobile ${ }^{\mathrm{vi}}$. Justine and Margot both work in the City, and discuss how they address the contradiction between the demands of their children and their employment. 
Realistically it is hard to allow people with children just to work 9-5 so one way or another those people find other hours to work so when I went back to work the last time I used, after my son had gone to bed, I used to do a couple of hours at home... I'd say 10 hours a day isn't unusual, and the bank that we've just merged with I would say 12 hours was quite common there....I was still very determined to have a career, because with one [child] I think you can do it. I think with two you have to face up to the fact that you probably have to take more of a back seat...but given that my husband earns more than I do, it means inevitably that my career has to be kind of put on hold because one of us has to go and pick the children up from nursery (Justine, B, City accountant, husband also accountant)

Margot who has three young children, talks of the new Chairman of her bank, responsible for creating some policy change in an organisation previously unsympathetic to flexible or part time working patterns. Even so the emotional tensions remain.

He's been the first one since the bank's creation who's very much for what he calls the 'work-life balance scheme'... Until now you got part time if your boss wanted to give you part time. If your immediate boss didn't want to give you part time nobody cared. You didn't get it, that was it....Now [they] have to come up with something, because they have no option...I leave work at $6 \mathrm{pm} . .$. But what I've done is I've worked every evening on average, you know two or three hours after the children are asleep. When you are pregnant and everything it made the whole thing a little bit stressful [When I came back to work after first child I felt] very guilty, felt unsafe a little bit, was not quite sure what was happening at home. Physically missed the baby in my arms. It was really very much a physical feeling. And that was for the first six weeks and then you know, I slowly got over it...Still the guilt of not being at home, that's something that never goes away I think for most mothers (Margot, B, lawyer in bank) 
Occupations demanding long hours and participation in office politics are not confined to the City. Gaby is an architect and talks of the difficulty of being on the periphery of 'two worlds'. She does not want to immerse herself in either to the exclusion of the other, but the two do not easily segue. Neither does she feel there is any viable alternative to working four days a week.

The only sad thing, and this is just you know, it'd be really nice, it feels she [carer] gets to raise [son] and I don't. You know it's just you know, you're giving your baby to a complete stranger, but as complete strangers go, I feel quite, quite good that it's her...I don't think I would have wanted to take five years off but I certainly would be quite happy if I could have taken his whole first year off...Meanwhile at work I feel it's so much this kind of work culture, and they all go out for drinks or whatever....If I were to go out of it for five years it' $\mathrm{d}$ be harder to come back in ..... [if I worked three days rather than four] I'd feel so out of the loop and I wouldn't be able to attend meetings and therefore it'd be all second hand information and that's a power thing. (Gaby).

Gaby seems to be caught acutely between the two worlds of which she speaks. She talks with intensity about not seeing her children enough, her awareness that they are growing and that she is not there to act as a constant witness. Neither is she a full time participant in the culture of employment. However, her ambivalence about full time motherhood is revealed in the way she talks about her thought processes adapting to her return to work.

I also feel it's very hard to come out of being off and your brain just kind of turns to mush. Or it's not turned to mush, but is concentrating other things....

Although she quickly denies that motherhood turns your brain to 'mush', she then continues by saying 'it's kind of like reverse senility. 'I, kind of, started and couldn't remember anything, my head was in a cloud' ( or 'fog', elsewhere) (also McMahon 1995 p.226). Motherhood is clearly not seen as intellectually demanding. Rather motherhood 
embodies a different relationship between self and others, a relationship that is traditionally expressed in physical and emotional terms, rather than through the more abstract intellectual challenge of paid employment. It seems that Enlightenment dichotomies of nature and body versus the mind and culture are still in play here. Although women now participate very markedly in the public sphere, the pull of nurturing is still strong. This is problematic only insofar as nurturing is understood as a 'timeless and unalterable activity, guided by natural laws and associated with the natural attributes of women' (Everingham 1994 p.6) and largely incompatible with the exercise of agency and free will.

Thus organising participation in two worlds which have contrasting rhythms and values, remains a process fraught with ideological and practical difficulties. However this is understood in the UK solely as a problem of management for individual women (Grace 1998). As McMahon comments, 'the political, organisational and ideological contradiction between those spheres [caring at home and paid work] are reduced to the private problem of organising and scheduling, a private problem of balancing' (1995, p.206). We consider below the ideology of 'intensive mothering' which appears to address the tensions between the demands of children and paid employment, although with considerable costs to the mother. Another way forward is indicated by Duncan and colleagues (2003) in their study of mothers' attitudes towards paid work. They identify three stances or 'gendered moral rationalities' which the mothers adopted which bear some similarity to positions on our investment continuum. They are 'primarily mother', 'primarily worker' or 'mother/worker integral'. The latter position held mainly by respondents of African/Caribbean origin and involved understanding full-time employment as part of good mothering (2003, p.313). Duncan et al comment that 'mothers gendered moral rationalities still involve their primary responsibility for their children [but] how mothers exercise that responsibility varies' (p.327). The 'mother/worker integral' rationality appears to have the potential to resolve the tension between Hay's (1996) 'opposing logics' of the private family sphere and public marketplace. 
It is those with mother/worker integral views who seem to lie on the cutting edge of changing gender divisions in that they conceived providing for their children through paid work as part of mothering,' (Duncan et al 2003, p.325).

But as our discussion and the data above indicate, such resolutions can be fragile and costly to maintain, both financially and emotionally. Clearly more work needs to be done in exploring the attitudes towards work/life balance, and the settlements made by mothers from a range of social class and ethnic groups.

\section{Intensive mothering}

'The anxiety that one is not doing enough for the child' (Furedi 2001 p.65) persists for most whether working or not. Hays' (1996) research with middle and working class American women and Windebank's (1999) work with French women argue that even those who work adopt intensive styles of mothering. Hays and others points to the conflation of 'good' mothering with intensive mothering, what Walkerdine and Lucy (1989) refer to as 'sensitive mothering', or Manicom (1984) calls 'total mothering'. This describes the heavy investment of the mother's time, energy, money and emotional commitment into enhancing the child's intellectual, physical, social and emotional development. The toll upon the mother is considerable; 'having it all' becomes 'doing it all' (Benn 1998).

One might argue that employed mothers in the middle class have more to gain from reconstructing ideas about appropriate child rearing than any other group not only because their higher salaries mean that more money is at stake but also because intensive mothering potentially interferes with their career trajectory....But as I have suggested, middle class women are in some respects those who go about the task of child rearing with the greatest intensity, (Hays 1996 p.151)

Yet for all they [working mothers] do to meet the needs of their children, they still express some ambivalence about working outside the home. And they still 
resolve this ambivalence by returning to the logic of intensive mothering and reminding the observer that ultimately they are most interested in what is best for their kids. This is striking (Hays 1996 p.149)

This ambivalence is, in good part, a consequence of our confusion over the status of motherhood. Women who have children stand at the nexus of two competing policy discourses. One, rooted in economic policy, de-genders a woman (officially at least) portraying her as a skilled and valued worker, contributing to the economy and capable of professional fulfilment and satisfaction. The other discourse, rooted in social policy, we could say almost excessively genders her, and celebrates her 'natural' abilities. It understands 'good' mothering as the key to a child's successful development, placing the responsibility and onus on the mother. As a result, as Hays comments, many middle class mothers - like those in our research - whether in paid work or not practise a kind of professional motherhood. They take their children to a range of carefully planned activities. They agonise over their future schooling. They read parenting books and magazines but treat expertise cautiously, engaging in 'reflexive encounters with expert systems' (Giddens 1991). And they do all this whether they work outside the home or not. Indeed, as far as we can judge from the current data, all our respondents - whether engaged in paid work or not - could be described as 'professional mothers', practising 'intensive mothering'. Even those mothers who work for long hours and are in Hakim's (2000) terms career-oriented and 'work centred', would not, we feel, view their children as Hakim suggests as a 'weekend hobby' (Hakim 2000, p.164). The women experience tension between their deep, intense love for their children and a sense of responsibility for all aspects of a child's development - an acceptance of intensive mothering, which acts as dominant 'cultural script' (McMahon 1995) - versus the grind, boredom, and lack of autonomy and status inherent in looking after small children. Here they reflect a fundamental societal ambivalence about the status of caring for and by extension the status of children themselves (Brannen \& Moss 2003). This dilemma between love and tedium, responsibility and marginalisation is experienced for the most part by women not their partners. 


\section{The 'Second Shift' (Hochschild 1989)}

Along with other writers, researchers and commentators in this area, we have already noted the placing of childcare as the woman's responsibility. In a majority of cases it is the woman who makes the choice, having done all the research, and her salary pays for the care (Vincent \& Ball 2001, Vincent et al 2004). Indeed this situation seems unchanged from that found by Brannen \& Moss in their study of dual career families in the late 1980s (Brannen \& Moss 1991).

Writing in an American context, Hochschild also noted that in middle class dual career families, women still bear the brunt of the childcare and domestic responsibilities. Rather than men increasing their contribution, the 'solution' is more often for the care responsibilities to be pushed 'down' to, particularly in the US context, lower skilled, often immigrant workers (Hochschild 2003, Wrigley 1995). Ehrenreich makes the same point in relation to housework, contending that 'in the chore wars of the 1970s and 1980s, women gained a little ground, but overall...men won. Enter the cleaning lady as dea ex machina' (Ehrenreich 2003 p.89).

This is not the situation we expected to find amongst our respondents; with the "new man' emerging in the 1990s in the UK as an icon of considerable cultural power (Benn 1998), surely research on childcare in the 2000s would show the new man's role was now a mature and established one? Apparently not. Our respondents suggested that in two career families the pace of one partner had to slow somewhat in order to encompass caring responsibilities. It was the women who moved to part time work, gave up work, or in a few cases stayed full time but worked more 'limited' hours. Although we heard rumours of some, we found no 'stay-at-home' fathers in our research settings. As McKie and colleagues note, 'the ideological connection between women and caring (additionally located in the household) continues to underpin public, social and employment policies and notions of 'the family' (2001 p.234).

When he's here he's very involved indeed. He's - I can completely - I mean not that I do - but I can completely just walk out of the door and he would 
know what to do without me giving any sort of instructions or leaving anything to sort out.......But he's not here very much. He works very long hours so he sees them ten, fifteen minutes in the morning and then that's it for the week, usually part from the weekend [....] I find it really interesting because...we're both high achieving people, we're both successful in our field, and then you become a mother and suddenly, it's not for any reason other than because you want to be there for your children, and because you have to have some way of coping with the situation, suddenly your roles changed completely...And you suddenly look at yourself and think 'blimey, I'm in these really traditional roles, and how the hell did we get here?'.... I think these are things which are so fundamental that they're very deep rooted and you don't know that they exist until you're actually in that situation. (Kathryn, B, she is a part time speech therapist, he is a lawyer)

He doesn't see - he adores the children - he probably sees them two or three nights a week, just because they're both in bed at seven o'clock (Nancy, B, at home) (See also Justine above)

These extracts contains a number of interesting points. There is the implied assertion that Kathryn's partner is a 'good' carer, because he knows what to do with the children without any instruction from her. It is still difficult to imagine a father talking like this about a mother. Other research in this area also reveals women talking about partners who share in childcare and other domestic responsibilities in similar terms: as 'good' men whom they are 'lucky' to have (Hays 1996, McMahon 1995, Jordan et al 1992). Men's absence from the home is understood as the reason why they can't be more involved, but the existence of any element of choice about how family responsibilities are organised tends not to be recognised (but see below). Of course, such choice is not open to all, but some of these professional, successful men have earned a degree of financial and working autonomy in terms of independence, and have perhaps more opportunities to choose in favour of time with their children than is commonly recognised. This is in no way to suggest that these men are simply reneging on their responsibilities to their children or 
that they do not love them sufficiently, rather to assert that the way in which motherhood and fatherhood are socially constructed: as different roles, conducted in different ways with different requirements. Thus male careers and working patterns still appear to retain priority even in dual career households (see also Hatten et al 2002, Warin et al 1999, Gregson \& Lowe 1994). Bringing up children remains, for the overwhelming majority, the work of women, whether mothers or other women carers. Many women in the study went to considerable lengths to explain and justify the impossibilities - practical and dispositional - of their partner taking on a more significant role in childcare.

Well, he just- well, he's conventional in the sense that he's a man who goes to work and..... I wouldn't want to call him a chauvinist because I wouldn't want to be married to a chauvinist. But he is, he's very male, you know, he's very- he can't do any more than he's doing. And, basically, what he'd- so he can- we have a life where he can leave for work at half past eight...so he sees us in the morning. And then he comes- he can come back at six. But after, after a half an hour he starts thinking: 'so when's the bath gonna be? So when are we gonna get them into bed because I've got work to do? And when are we gonna eat?' And there's a kind of- this kind of pressure....because he comes home early and so he's got to do some work after supper. And so we have- and I, you know, we've got to change this because I can't live with it.....He does the bath while I, you know, tidy up the supper or make our supper, or.... But, you know, I'm never, I'm never doing nothing [...] It's impossible, I think, for him to actually have that much involvement, just out of circumstance, not, not because he's not interested (Connie, SN)

The traditional gender roles assume a naturalness and inevitability, which appears to at least complicate Hakim's (2000) notion of preferences. A frequent phrase used by female respondents when describing the re-assertion of tradional divisions of labour after having children was that it 'just happened'. Another respondent, Linda described how she and her husband both worked a four day a week when their first child was a baby (they now 
have three children). She made the point that as the woman is seen by others as the main carer in the couple, slowly the woman becomes the main carer even if the situation started out differently. However, this is also her choice, whereas her partner chooses slightly differently.

There was an article on him [in an in-house magazine] because he was in the first man [in the organisation] who was allowed to work a four day week for parental responsibility[.... I always try and work a three day week. Every time [partner] has moved jobs...he always tries to move towards a four day week..and sometimes he's been successful and sometimes not....[He is self employed now] and he's very much trying to work a three day week..He does a lot more because he is around and he genuinely likes to do things with the children, but he doesn't any longer want to commit a day to that [childcare] and there's no need actually at the moment with the children...I think it happened over time. And I'm, I'm much more clear that I want to spend quite a lot and especially with [eldest son] starting a new [secondary] school, [youngest son] starting nursery, and [middle son] always finds it hard to move to a new teacher ... So I wanted to be around much more and I feel that's my choice. But it's much more gender stereotyped than we would have imagined when we were together before having children (Linda, B., both self employed, he is an education consultant, she a charity consultant)

The interesting point of course is why Linda feels the need to spend regular time looking after the children whilst her partner does not. Her comment about choice should not be overlooked; although there were some hints of resentment from women (see Connie above) these were rare. Whilst it is indeed possible, as Hays suggests that mothers are involved in 'strategies to downplay gender inequities' not wanting others or themselves to realise the extent of the imbalance in domestic duties (1996 p.105), there is also the possibility that in relation to their children, women wish to respond wholeheartedly to what Melissa Benn (1998, p.233) calls the 'extraordinary pull, joyful and burdensome, of motherhood'. The women in our study did feel they had a choice and they made that 
choice in favour of their children, rather than their careers or their own time. But of course it was a choice that works within a 'dominant cultural script' (and is therefore simpler to make), a cultural script that posits men's involvement as laudatory but still voluntary (Hochschild 2003, McMahon 1995, also Jordan et al 1992). Fathers are simply not understood to be so central to the emotional and physical well-being of their children as mothers are. This points to yet another ambivalence in attitudes towards mothers, because some mothers (young, lone mothers for example) are at risk of not being seen as sufficient, and their children - especially boys - deprived of male influence.

The perception of greater sharing of domestic and childcare responsibilities between mother and father is, Benn (1998) contends, just that, a perception, not a reality. The commitment may often be qualitatively as well as quantitatively different as women may act as 'the organisational and emotional intelligence behind the scenes' (p.95). Our data offers support, therefore to La Rossa's (1988) argument (quoted in Valentine 1997) that there is a gap between the culture of fatherhood - what is socially acceptable and appropriate for men to do as parents, and the conduct of fatherhood - what men actually do. La Rossa argues further that while the conduct of motherhood may have got more diverse in recent years (e.g. working mothers, single mothers), the culture of motherhood (the expectations of mothers and the romanticisation of motherhood) has stayed largely the same. Further, Sarah Riley's (2003) study of the way in which men talk about gender roles highlights the power of employment in constructing male identity and the persistence of the employment- (real) work coupling (also Hatten et al 2002, Warin et al 1999). She focused on the attitudes of a sample group (similar to ours) of 'professional white heterosexual men' (p.99), to a range of vignettes, such as one where a man, made redundant, is asked to take on more domestic responsibilities by his employed partner. She notes that the men interviewed were aware of and often employed egalitarian discourses, but did so in a way that left the legitimacy of traditional gender divisions unchallenged. She concludes that, 'without alternative meanings associated with masculinity the loss of the provider role (which is coupled with masculinity) becomes equated with a loss of male-self' (Riley 2003 p.111). 
Taking up the issue of men's care being qualitatively different, the respondents in Hays' (1996) study argue that when men do look after their children, their approach is different to their partners. When they liase with the carer they may not ask the right questions or remember names or get the children properly equipped for the day (see also Hatten et al 2002 on the practices of fatherhood). This was reiterated in our study, Angie, for example, commented that despite the fact that her child's creche took place in their home, her partner did not remember the other children's names.

He's much more laid back than me, he doesn't get wound up like me.....He doesn't know anyone's names, [other parents] he doesn't remember names of children or anything like that... (Angie, SN)

Hannah discusses the different ways her partner and herself relate to the children, the amount of time they spend respectively is also an issue here, but not the main one, Hannah is describing a difference in approach between the two adults. The strictures of 'intensive mothering' - responding quickly and sensitively to your children - have not had as much impact upon her partner as upon herself. In common with the women already cited, Hannah stresses both that these divisions appeared to 'just happen' without any planning, as couples 'fall' into pre-assigned gender roles ${ }^{\mathrm{vii}}$ and also, again, that the increased time she spends with and caring for the children is her choice.

I think we have a very different way of caring for the children...It's difficult, it's difficult to explain really. I think I take a lot more of the planning side of things on board.....I sometimes get a bit frustrated if we're going out somewhere for a day trip, I'm always the one who gets everything ready. I mean he will do it, but I will say 'we need to take some milk for [toddler]'. That's what I mean by planning or thinking ahead to what's next. He will be much more 'oh, they'll make do'.....He is very good at certain ways of playing, but it's like bursts of activity. He's also quite good about detaching himself. I find it really hard to, like if I'm in the room with the children, I mean he would manage to sit there and read a book or a newspaper. But I 
would never manage that. It's like the way you set up your interaction with the children I suppose and what they expect of you. And they always expect me to respond immediately, I think and I do [...] I wouldn't say [the division of domestic chores] is necessarily uneven, but with the children, sometimes I do feel I take more of the burden, but I think it's partly just because, kind of the things which I think are important to do, you know, are the things that I want to do....It's funny isn't it how you, like, you don't necessarily discuss the divisions, it just sort of happens somehow (Hannah, SN, she is HE lecturer, he is IT manager)

To date we have only two couples in the study (additional to the first 50 respondents whose experiences form the main part of this paper) who have clearly organised their life in a way which departs from traditional norms. Both these fathers are freelance workers, one has always been so, the second made a decision to move to freelance work to spend more time with his children (although he is not a full time carer). Gustavo, like his partner, was born outside England and attended progressive schools. He helps out at a small co-operative nursery, established by his partner, in Stoke Newington. Like the women cited above, he emphasises that it is his choice to be involved to the extent that he is.

Being a freelance I'm able to do it; and as well as a proper belief - I want to do it. I don't know, I don't really know about the rest of the families but I see that perhaps I'm the father that more often works at [ie helps at] the nursery. I don't know if it's because I have more time, or because I really want to do it, or... And maybe one of the reasons that I don't want to be- work in a fulltime job - is because I've always been very proud of this - myself being free to decide what I want to do. And this thing about having a child, to be involved is one of my choices (Gustavo, photographer, SN)

Tony, also born and educated outside of England, similarly emphasises the choices he has made and contrasts them with those made by some of his peers. 
I've worked in IT for a long time and the hours are really long and a lot of people I know work in that industry - they don't see much of their kids and they're very stressed when they're at home...I really don't see the point of being a father if you can't be there for your kids. I understand sometimes it is financially difficult, and you have to take what jobs come along, but equally I know a lot of men - when I worked on consultancy - who couldn't wait to work on weekends...I think I was seen as some sort of weirdo because I actually enjoy time with my family (Tony, B. now freelance journalist)

As we said, Gustavo and Tony are exceptions. Their exceptionality highlights the uniformity of their male peers, who tend to inhabit the periphery of childrearing. We clearly need to do more work to understand the choices of these men and their experiences of stress and ambivalence, and so are discussing these issues during on-going re-interviews, some of which involve both the mother and father.

The apparently pre- dominant set of familial relationships can be located within a policy framework. Ros Edwards (2002) cites Pfau-Effingers work on notions of 'good' childhood as understood differently in particular welfare regimes. She contrasts 'the male breadwinner/female part time carer provider’ model (eg Britain, New Zealand, Switzerland and the USA) with 'Dual breadwinner/state child care provider' model (eg Norway, Finland, Sweden). This means that even for those women who work, the carer is a mother substitute in the former category of welfare policy regimes. This is referred to by Edwards as 'familialisation' rather than 'institutionalisation'. As part of familialisation practices, care is organised by individual households and often in individual homes, rather than in state institutions. Even when in the more public realm of nurseries, familialisation leads to an emphasis on the small and intimate (a main reason given for establishing the three small, co-operative nurseries in our study). Familialisation can prevail amongst middle class families as the home is not generally seen as dysfunctional, as may be the case for some working class families. 


\section{Conclusion}

There may be those reading this paper who are unhappy with our dualisms, our deployment of the terms 'men' and 'women', seeing our usage as essentialist, sweeping, and simplistic. We are referring in the main, specifically to the people who make up our sample, and who are broadly homogeneous in terms of class, ethnicity and educational background. Even given this caveat we too remain a little uneasy. We had expected more differences between families, a wider range of settlements concerning childcare and childrearing, a wider variety of roles and responsibilities. However we found a surprisingly uniform picture, a confirmation of findings from the body of previous research cited here. It is possible that our questions did not elicit the nuanced and detailed information that would give rise to a more heterogeneous portrayal of the domestic and working lives of the mothers and fathers in the study. However, we can find no evidence for this on reading the finely grained, open, and forthcoming accounts presented in the transcripts. What we have found difficult was finding fathers who were significantly involved in childcare, and we are concentrating our resources during the remaining round of interviews on the fathers, exploring the balances they maintain between work and home.

However, at this stage in our analysis, it does appear that despite the social and economic advantages of this group, despite the educational and labour market opportunities experienced by the women, that these men and women are not presenting a serious challenge to a traditional understanding of family relationships, a tradition which focuses on the ties binding women and children together whilst locating men on the periphery. This peripherality does not refer to the affection in which the men hold and are held by their children but rather suggests that the manifestations of that sense of love, affection and responsibility for their children - working long hours for instance - places fathers somewhat at a distance from children. It is thus the mothers who remain the key figure through the heat and noise of early childhood, even if they themselves are also engaged in paid work. This has considerable implications for the orientation of women towards the labour market. In place of the full investment in their careers that most made before their 
children, those women who return to work inhabit a series temporary settlements with which they are more or less satisfied. They continue to work with and around contradiction. As Beck says, 'the lives of women are pulled back and forth by the contradiction between liberation from and reconnection to the old ascribed role,' (1992, p.111-2).

\section{References}

Bailey, Lucy (1999) Refracted selves? A study of changes in self-identity in the transition to motherhood, Sociology, 33, 2 pp.335-352.

Ball, Stephen, Vincent, Carol, Kemp, Sophie and Pietikainen, Soile (2005 forthcoming) Middle class fractions and childcare in two London settings, Sociological Review

Beck Ulrich, \& Beck-Gernsheim, Elizabeth, (1995) The Normal Chaos Of Love, Cambridge: Polity Press.

Beck, Ulrich, (1992). Risk Society: Towards a New Modernity. Newbury Park, CA.: Sage.

Benn, Melissa, (1998) Madonna and Child London: Jonathan Cape Brannen, Julia, \& Moss, Peter (1991) Managing Mothers: Dual Earner Households After Maternity Leave. London: Unwin Hyman.

Brannen, Julia, \& Moss, Peter, (2003) Rethinking Children's Care Buckingham: OUP. Crompton, Rosemary, (2001) The gendered restructuring of the middle classes: employment and caring. In Rosemary Crompton, Fiona Devine, Mike Savage and Jo Scott (eds.) Renewing Class Analysis (pp.165-184) Oxford: Blackwells Daycare Trust (2001) Quality Matters. Ensuring Childcare benefits Children, London: The Daycare Trust.

Duncan, Simon, Edwards, Ros, Reynolds, Tracey (2003) Motherhood, paid work and partnering: values and theories Work, Employment and Society, 17, 2, 309-330. 
Edwards, Ros \& Duncan, Simon (1996) Rational economic man or lone mothers in context? The uptake of paid work. In Elizabeth Bortolaia Silva (Ed.) Good Enough Mothering? (pp.114-129) London: New York.

Edwards, Ros (2002) Conceptualising relationships between home and school in children's lives. In Ros Edwards (ed.) Children, Home and School: Regulation, Autonomy or Connection? (pp.1-23) London: RoutledgeFalmer

Ehrenreich, Barbara, (2003) Maid to order. In Barbara Ehrenreich \& Arlie Russel Hochschild (Eds.) Global Women (pp.85-103) London: Granta Everingham, Christine (1994) Motherhood and Modernity : an investigation into the rational dimension of mothering. Buckingham: Open University Press

Furedi, Frank (2001) Paranoid Parenting. Harmondsworth, Penguin Books Giddens, Anthony, (1991) Modernity and Self-Identity: Self and Society in the Late Modern Age. Cambridge: Polity Press.

Goldthorpe, John (1995) The Service Class Revisited. In Tim Butler and Mike Savage (Eds) Social Change and the Middle Classes (pp.313-329). London: University College London Press.

Grace, Marty (1998) The work of caring for young children: priceless or worthless? Women's Studies International Forum, 21, 4, 401-413.

Gregson, Nicky and Lowe, Michelle (1994) Waged domestic labour and the renegotiation of the domestic division of labour within dual career households, Sociology, 28, 1,55-78. Hakim, Catherine, (2000) Work-Lifestyle Choices in the $21^{\text {st }}$ Century, Oxford: oxford University Press.

Hall, Sarah, (2004) Byers presses for end to national childcare lottery, The Guardian, $30 / 4 / 04$

Hatten, Warren, Vinter, Louise and Williams, Rachel (2002) Dads on Dads: needs and expectations at home and at work, London: EOC/Mori Hays, Sharon, (1996) The Cultural Contradictions of Motherhood, New Haven: Yale University Press.

Hochschild, Arlie Russell, (1989) The Second Shift : Working Parents and the Revolution at Home New York: Viking. 
Hochschild, A Arlie Russell. (2003) Love and gold. In Barbara Ehrenreich \& Arlie Russell Hochschild (eds.) Global Women London: Granta

Holloway, Sarah, (1998) Local childcare cultures: moral geographies of mothering and the social organisation of pre-school children, Gender, Place and Culture, 5, 1, 29-53. Hondagneu-Sotelo, Pierette, (2003) Blow ups and other unhappy endings. In Barbara Ehrenreich \& Arlie Russell Hochschild (eds.) Global Women (pp.55-69) London: Granta Jordan, Bill et al (1992) Trapped in Poverty? London: Routledge.

Jordan, Bill et al (1994) Putting the Family First London: UCL Press

Manicom, Ann (1984) Feminist frameworks and teacher education, Journal of Education $166,1,77-102$.

McKie, Linda, Bowlby, Sophia, \& Gregory, Susan, (2001) Gender, caring and employment in Britain, Journal of Social Policy, 30, 2, 233-258.

McMahon, Mary (1995) Engendering Motherhood New York: Guildford Press. Mooney, Anne, (2003) Mother, teacher, nurse? How childminders define their role. In Julia Brannen and Peter Moss (eds.) Rethinking Children's Care, (pp.131-145) Buckingham: Open University Press.

Padfield, Ian, \& Proctor, Maureen, (1998) Young Adult Women, Work and Family: Living a contradiction London: Mansell

Pearson, Alison, (2002) 'I don't know how she does it!'London: Vintage

Phoenix, Ann, (1991) Young Mothers? Cambridge: Polity Press.

Skeggs, Beverley (1997) Formations of Class and Gender: Becoming Respectable London: Sage.

Reynolds, Tracey, Callender, Claire \& Edwards, Ros (2003) Caring and Counting: The Impact of Mothers' Employment on Family Relationships. Bristol: Policy Press.

Riley, Sarah (2003) The management of the traditional male role: a discourse analysis of the constructions and functions of provision, Journal of Gender Studies, 12, 2, 99-113. Stephens, Janet (1999) A fight for her time: challenges facing professional mothers In Linda McKie, Sophia Bowlby \& Susan Gregory (eds.) Gender, Power and the Household (pp.99-115) Basingstoke: Macmillan Valentine, Gill (1997) 'My son's a bit dizzy.' 'My wife's a bit soft': gender, children and cultures of parenting Gender, Place and Culture, 4, 1, 37-62. 
Vincent, Carol (2000) Including Parents?Education, citizenship and parental agency. Buckingham: Open University Press.

Vincent, Carol and Stephen J. Ball (2001) A Market in Love? Choosing pre-school child care British Educational Research Journal 27,5, 633-651.

Vincent, Carol, Ball, Stephen, J and Kemp Sophie, (2004 ) 'The Social Geography of Child Care: making up a middle class child' British Journal of Sociology of Education, 25, 2, 229-244.

Walkerdine, Valerie, \& Lucey, Helen, (1989) Democracy in the Kitchen. London: Virago.

Warin, Jo, Solomon, Yvette, Lewis, Charlie \& Langford, Wendy (1999) Fathers, Work and Family Life. London: Family Policy Studies Centre/Joseph Rowntree Foundation Windebank, Jan (1999) Political motherhood and the everyday experiences of mothering: a comparison of the child care strategies of French and British working mothers Journal of Social Policy, 28, 1, 1-25.

Wrigley, Julia, (1995) Other People's Children. New York: Basic Books/Harper 
${ }^{i}$ As Goldthorpe (1995 p. 314) makes very clear; 'the service class is a class of employees'. The main problem of demarcation is that of distinguishing them from other sorts of employees. There are two elements to this; first, benefits of employment over and above salary; (pension rights and so on); second, some degree of professional autonomy and managerial or administrative authority. Despite on-going changes in the labour market these criteria do still provide a fairly robust basis for distinguishing service class employees from other middle class groups, specifically the 'intermediate' middle class. That is, those employed in routine, low-autonomy, white-collar jobs.

ii $£ 9000$ is equivalent to 16,000 US dollars or 13,000 Euros

iii This sum is equivalent to 62,000-71,000 US dollars and 51,500-59,000 euros.

iv One of the respondent women was of Asian origin, a further two women were in mixed race relationships with men of African/Caribbean origin. One woman was a lesbian who had recently split up with her partner. One of the heterosexual partnerships also broke up but not during the time frame referred to in this paper.

$\checkmark$ Monica's quote below does assume the professionalism of carers, a view of this low paid female workforce, which is not always shared.

vi Thanks to Dr Lora Bartlett from the University of California at Santa Cruz for introducing us to this term.

vii Elsewhere in the interview, she notes that they share cooking and washing, she purees the baby's food, he pays the bills and mends punctures on their bikes, and they have a cleaning lady 'which is essential as he would never do any cleaning'. 